Journal of Bangladesh Academy of Sciences, Vol. 35, No. 1, 99-111, 2011

\title{
OPTICAL PROPERTIES OF UNDOPED AND INDIUM-DOPED TIN OXIDE THIN FILMS
}

FATEMA REZWANA CHOWDHURY, SHAMIMA CHOUDHURY*1 FIROZ HASAN ${ }^{2}$ AND TAHMINA BEGUM ${ }^{2}$

Electrical and Computer Engineering, University of Alberta, Edmonton, Canada

\section{ABSTRACT}

Thin films of Tin Oxide $\left(\mathrm{SnO}_{2}\right)$, having thickness of $200 \mathrm{~nm}$, were formed on to glass substrates by thermal evaporation of high-purity $\mathrm{SnO}_{2}$ powder in vacuum at various substrate temperatures $\left(\mathrm{T}_{\mathrm{S}}\right)$, ranging between 25 and $200^{\circ} \mathrm{C}$. $\mathrm{SnO}_{2}$ films with varying thickness were also prepared for a fixed $\mathrm{T}_{\mathrm{S}}=100^{\circ} \mathrm{C}$. Further, doping of $\mathrm{SnO}_{2}$ films with Indium (In) was accomplished through solid state diffusion process by successive deposition of $\mathrm{SnO}_{2}$ and $\mathrm{In}$ films and subsequent annealing at $200^{\circ} \mathrm{C}$ for 10 minutes. Both undoped and doped films were characterized optically by UV-VIS-NIR spectrophotometry in the photon wavelength ranging from 300 to $2500 \mathrm{~nm}$. In the visible photon wavelength range, the average optical transmittance (T\%) of the films with varying $\mathrm{T}_{\mathrm{S}}$ was found to be $85 \%$. The maximum value of $\mathrm{T} \%$ was found to be $89 \%$ around the wavelength of $700 \mathrm{~nm}$. The variation of absorption coefficient with photon energy in the fundamental absorption region is the steepest for $\mathrm{T}_{\mathrm{S}}=100^{\circ} \mathrm{C}$. The sub-band gap (SBG) absorption is also minimum for this $\mathrm{T}_{\mathrm{s}}$. A fluctuating behavior of the band gap energy $\left(\mathrm{E}_{\mathrm{g}}\right)$ with $\mathrm{T}_{\mathrm{s}}$ is observed attaining the highest value of $3.59 \mathrm{eV}$ for $\mathrm{T}_{\mathrm{s}}=100^{\circ} \mathrm{C}$. The band gap energy increases with thickness but $\mathrm{T} \%$ in the visible range decreases. The $\mathrm{T} \%$ in the visible range varies inversely with indium doping, being highest for undoped films. The $\mathrm{E}_{\mathrm{g}}$ increases upto $2 \mathrm{wt} \%$ In doping and gradually decreases for enhanced doping. It seems reasonable to conclude that In doping does not bring favorable optical characteristics. Undoped $\mathrm{SnO}_{2}$ films having thickness of $200 \mathrm{~nm}$ and formed at substrate temperature of $100^{\circ} \mathrm{C}$ yield essential acceptable properties for photovoltaic applications.

Key words: Tin oxide films, Indium doping, Transmittance, Band gap energy

\section{INTRODUCTION}

Tin Oxide $\left(\mathrm{SnO}_{2}\right)$ is a wide band gap n- type semiconductor, which can be efficiently used as transparent conducting oxide. Because of its unique electrical and optical properties, $\mathrm{SnO}_{2}$ thin films have been widely used in photocell devices, and optoelectrical displays. The films are chemically inert, mechanically hard and can resist high temperature. Indium tin oxide (ITO) thin film is a highly degenerate $n$-type semiconductor which has a low electrical resistivity of $2-4.3 \times 10^{-24} \Omega$-cm [Alam and Cameroon, 2000]. The low resistivity value of ITO films is due to a high carrier

\footnotetext{
*Corresponding author : <skc.phy@gmail.com>.

${ }^{1}$ Department of Physics, University of Dhaka, Dhaka-1000, Bangladesh.

${ }^{2}$ Experimental Physics Division, Atomic Energy Centre, Dhaka-1000, Bangladesh.
} 
concentration because the Fermi level $\left(E_{F}\right)$ is located above the conduction level $\left(E_{C}\right)$. The degeneracy is caused by both oxygen vacancies and substitutional tin dopants created during film deposition. The carrier concentration of high conductivity ITO films is in the range of $10^{20}-10^{21} \mathrm{~cm}^{-3}$.

Doped or undoped $\mathrm{SnO}_{2}$ films can be prepared by many methods such as spray pyrolysis (Afify et al, 1996; Nunes, 2001; Elangovan and Ramamurthi, 2003), electron beam evaporation [Das and Banerjee, 1987; Mika et al 2004], chemical vapor deposition [Jeong-Woon Bae et al, 2002], magnetron sputtering [Lee et al], pechini method [Legnani et al, 2007]. Thermal evaporation is the most widely used technique. It deposits materials quickly. High quality films are produced by thermal evaporation. This method is also substrate friendly.

In the present study, pure and $\mathrm{In}$ doped $\mathrm{SnO}_{2}$ thin films were prepared by thermal evaporation technique with different growth parameters. The effect of substrate temperature, thickness and doping percentage on the transmittance and reflectance were studied for $\mathrm{SnO}_{2}$ films. The value of absorption coefficient and optical band gap energy were obtained from the measurement of transmittance and reflectance of the films with the variation of photon wavelength.

\section{THEORETICAL FORMULATION}

When light is incident on a crystalline solid, a part of it is reflected $(\mathrm{R})$ at the surface, a part is transmitted (T) and rest is absorbed by the solid. The absorption pattern of the sample indicates the band structure of solid, energy gap between the valance band and conduction band, the nature of transition (allowed, forbidden, direct and indirect), etc.

Optical absorption is described quantitatively through the absorption co-efficient, $\alpha$. The $\alpha$ is the fraction of incident energy intensity decreased per unit distance in an absorbing medium and it can be expressed as,

$$
I=I_{0} \exp (-\alpha x)
$$

where $I_{0}$ is the intensity of incident light, $x$ is the thickness of the material and $I$ is the transmitted intensity.

In an absorbing material the $\alpha$ is related to the refractive index and the wavelength of the incident light. The refractive index, $\mathrm{n}$, is expressed as,

$$
n=n_{r}-i k
$$

where, $\mathrm{n}_{\mathrm{r}}$ is the real part of the refractive index and $k$ is called the extinction coefficient. The $\alpha$ of the material at a wavelength can be related with the extinction coefficient by, 


$$
\alpha=\frac{4 \pi k}{\lambda}
$$

The thickness of the films was checked using an infrared interference method, which depends on the reflectance characteristics of the films. In this method the thickness of a film is given by

$$
d=\frac{\Delta m}{2 \sqrt{n^{2}-\sin ^{2} \theta}} \frac{1}{\left(1 / \lambda_{1}\right)-\left(1 / \lambda_{2}\right)}
$$

where, $\mathrm{n}$ is the refractive index of the film, $\theta$ is the incident angle of light to the sample, $\lambda_{1}$ and $\lambda_{2}$ are the peak or valley wavelengths in the reflectance spectrum and $\Delta \mathrm{m}$ is the number of peaks or valleys between $\lambda_{1}$ and $\lambda_{2}$. The discrepancy between the values of thickness of the films measured in two methods (Edwards FTM5 Film thickness monitor and infrared interface method) was $\pm 10 \mathrm{~nm}$.

For transmittance $(\mathrm{T} \%)$ at normal incidence and reflectance $(\mathrm{R} \%)$ at near-normal incidence of light on the films, expressions for the multiple reflected systems have been given by Heavens (Heavens 1959). Tomlin (1972) simplified these expressions absorbing films on non-absorbing substrates and expressed them as equations given below:

$$
\begin{aligned}
& \frac{1+R}{T}=\frac{1}{4 n_{2}\left(n_{1}^{2}+k_{1}^{2}\right)}\left[\begin{array}{l}
\left(1+n_{1}^{2}+k_{1}^{2}\right)\left\{\left(n_{1}^{2}+n_{2}^{2}+k_{1}^{2}\right) \cosh 2 \alpha_{1}+2 n_{1} n_{2} \sinh 2 \alpha_{1}\right\} \\
+\left(1-n_{1}^{2}-k_{1}^{2}\right)\left\{\left(n_{1}^{2}-n_{2}^{2}+k_{1}^{2}\right) \cosh 2 \gamma_{1}+2 n_{2} k_{1} \sin 2 \gamma_{1}\right\}
\end{array}\right] \\
& \frac{1-R}{T}=\frac{1}{2 n_{2}\left(n_{1}^{2}+k_{1}^{2}\right)}\left[\begin{array}{l}
n_{1}\left\{\left(n_{1}^{2}+n_{2}^{2}+k_{1}^{2}\right) \sinh 2 \alpha_{1}+2 n_{1} n_{2} \cosh 2 \alpha_{1}\right\} \\
+k_{1}\left\{\left(n_{1}^{2}-n_{2}^{2}+k_{1}^{2}\right) \sinh 2 \gamma_{1}+2 n_{2} k_{1} \cos 2 \gamma_{1}\right\}
\end{array}\right]
\end{aligned}
$$

where, $\mathrm{n}_{1}$ and $\mathrm{n}_{2}$ are the refractive indices of the film and substrate respectively, $\mathrm{k}_{1}$ is the extinction-coefficient of the film, $\mathrm{n}_{2}=1.45, \alpha_{1}=\frac{2 \pi k_{1} d}{\lambda}$ and $\gamma_{1}=\frac{2 \pi n_{1} d}{\lambda}$, where $\lambda$ is the wavelength of light and $d$ is the thickness of the film. Equations (5) and (6) have been solved for $\mathrm{k}_{1}$ and $\mathrm{n}_{1}$ utilizing a computerized iteration process. The absorption coefficient, $\alpha$ was then calculated using $\alpha=\frac{4 \pi k_{1}}{\lambda}$. Dependence of $\alpha$ on photon energy has been analyzed with the existing models discussed subsequently in equation (1) to find the nature and extent of the band gap energy.

\section{EXPERIMENTAL}

Thin films of pure $\mathrm{SnO}_{2}$ and In doped $\mathrm{SnO}_{2}$ films were prepared on to chemically and ultrasonically cleaned glass substrate by thermal evaporation in vacuum $\left(\sim 10^{-6}\right.$ Torr $)$ using an oil diffusion evaporation unit (Edwards, E306, UK). The source material $\left(\mathrm{SnO}_{2}\right)$ 
was evaporated from a molybdenum boat and the substrate was placed at a distance of 3 $\mathrm{cm}$ above the source. The films were deposited at various substrate temperatures from $25-$ $200^{\circ} \mathrm{C}$ keeping thickness constant at $200 \mathrm{~nm}$. The thickness and rate of deposition of the films were measured in situ by a quartz crystal thickness monitor (FTM5, Edwards, UK).

Films of different thicknesses of 100, 150, 200, 250 and $300 \mathrm{~nm}$ were also grown at fixed substrate temperature of $100^{\circ} \mathrm{C}$.

Thin films of $\mathrm{In}$ doped $\mathrm{SnO}_{2}$ were deposited also on glass substrates. To achieve In doping, first we deposited In and then $\mathrm{SnO}_{2}$ using two different boats. We measured the mass of both Indium and Tin Oxide according to their percentage in total mass and deposited the corresponding thickness of the materials.

The In doping concentration was varied from 0 to $5 \%$, substrate temperature was kept constant at $100^{\circ} \mathrm{C}$ and total thickness was constant at $710 \mathrm{~nm}$. The above deposited films were annealed at $200^{\circ} \mathrm{C}$ for 10 minutes under a vacuum of $1.4 \times 10^{-3} \mathrm{~Pa}$.

The variations of transmittance and specular absolute reflectance of the films with wavelength of light incident on them were measured using a dual-beam-UV-VIS-NIR recording spectrophotometer (Shimadzu, UV-3100, Japan) in the photon wavelength range from 300 to $2500 \mathrm{~nm}$. An integrating sphere detected light signals coming from the samples. The $\alpha$ of the films was estimated using equation 3 .

To calculate the energy gap, $(\alpha h v)^{2}$ was plotted as a function of photon energy . The linear portion of the graph was then extended backward to find its intersecting point with $\mathrm{X}$ axis at zero $\alpha$. The value of photon energy at the intersecting point is equal to the energy gap for a particular film.

\section{RESULTS AND DISCUSSIONS}

Fig. 1 shows the optical transmittance spectra of tin oxide films prepared at different substrate temperatures (as deposited, 25, 50,100,150, 200 ${ }^{\circ} \mathrm{C}$ ) in the photon wavelength range of $300-2500 \mathrm{~nm}$. There are three regions in the transmission curve. In the first region (1500 $\mathrm{nm}<\lambda \leq 2500 \mathrm{~nm}$ ), the transmittance is low and almost constant. In the second region $(850 \mathrm{~nm} \leq \lambda \leq 1500 \mathrm{~nm})$, the transmittance increases smoothly attaining maximum at $850 \mathrm{~nm}$. The third region $(450 \mathrm{~nm} \leq \lambda \leq 550 \mathrm{~nm})$ is the absorption region where the transmittance falls abruptly. The interference pattern in the transmittance manifests the homogeneity of the film.

It is observed that average transmittance in the visible region is $85 \%$ and maximum transmittance is $89 \%$ at $700 \mathrm{~nm}$.It is also observed that transmittance is inversely proportional to substrate temperature in near infra red region. 


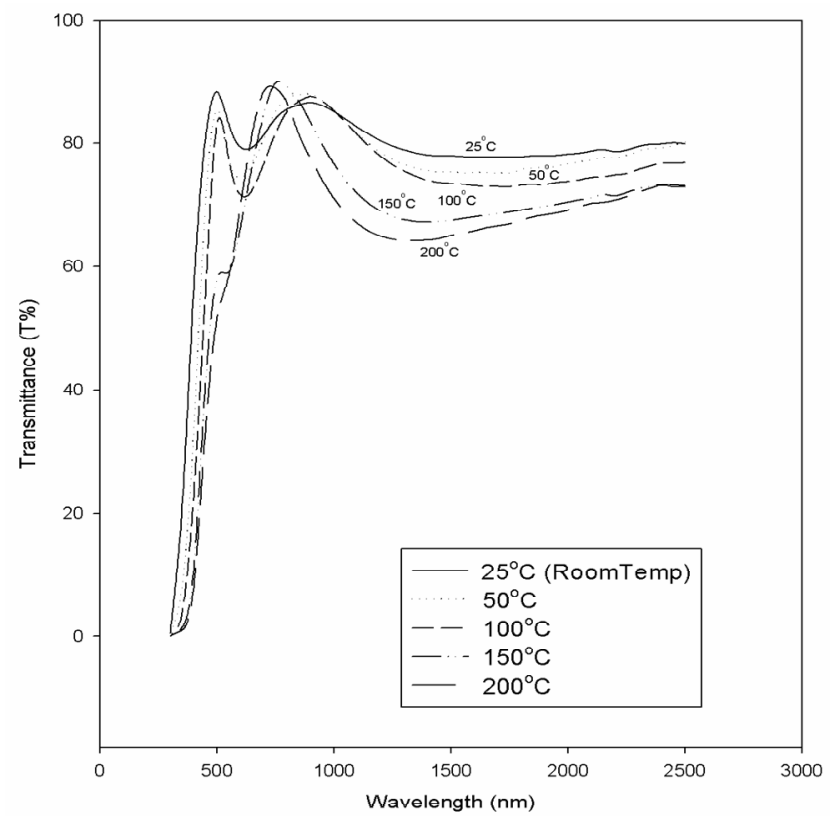

Fig. 1. Variation of optical transmittance $(\mathrm{T} \%)$ of $\mathrm{SnO}_{2}$ thin films deposited at various substrate temperatures with a fixed thickness of $200 \mathrm{~nm}$ with photon wavelength.

Fig. 2 shows the variation of absorption co-efficient, $\alpha$ of the films prepared at different substrate temperatures (as deposited, 25, 50,100,150, 200 ${ }^{\circ} \mathrm{C}$ ), with photon energy.

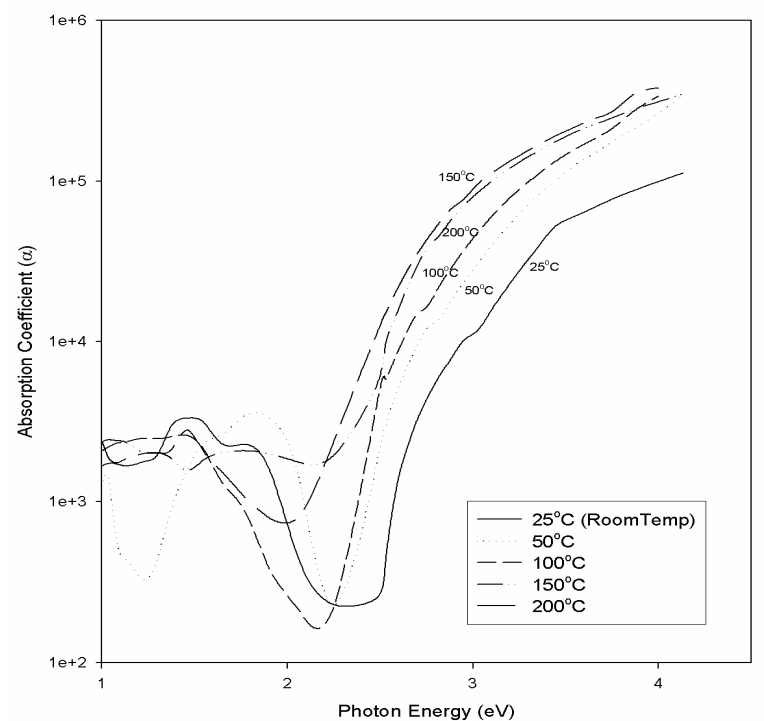

Fig. 2. Variation of absorption coefficient $(\alpha)$ of $\mathrm{SnO}_{2}$ thin films deposited at various substrate temperatures with a fixed thickness of $200 \mathrm{~nm}$ with photon energy. 
The rise of absorption co-efficient with photon energy at the fundamental absorption region is the steepest in case of the film deposited at the substrate temperature $100^{\circ} \mathrm{C}$. Sub band gap absorption is also minimum for this film. Near infrared absorption indicates the sub band gap (SBG) levels in the sample. The lesser the SBG, the better is the sample. From these observations we can conclude that the film which was deposited at the substrate temperature of $100^{\circ} \mathrm{C}$ is superior to all other films from the view point of optical absorption.

Fig. 3 shows the plot of $(\alpha h v)^{2}$ versus photon energy (hv) to find the value of band gap energy of the films prepared at different substrate temperatures. The extrapolation of the straight-line portion of the plot of $(\alpha h v)^{2}$ versus photon energy (hv) to zero absorption gives the direct band gap of the films. The band gap energies of the sample prepared at the substrate temperatures $25,50,100,150$ and $200^{\circ} \mathrm{C}$ are $3.42,3.56,3.59,3.38$ and 3.48 $\mathrm{eV}$, respectively as shown in Fig. 3. It is observed that the band gap energy adheres to literature value for the sample which was prepared at substrate temperature of $100^{\circ} \mathrm{C}$.

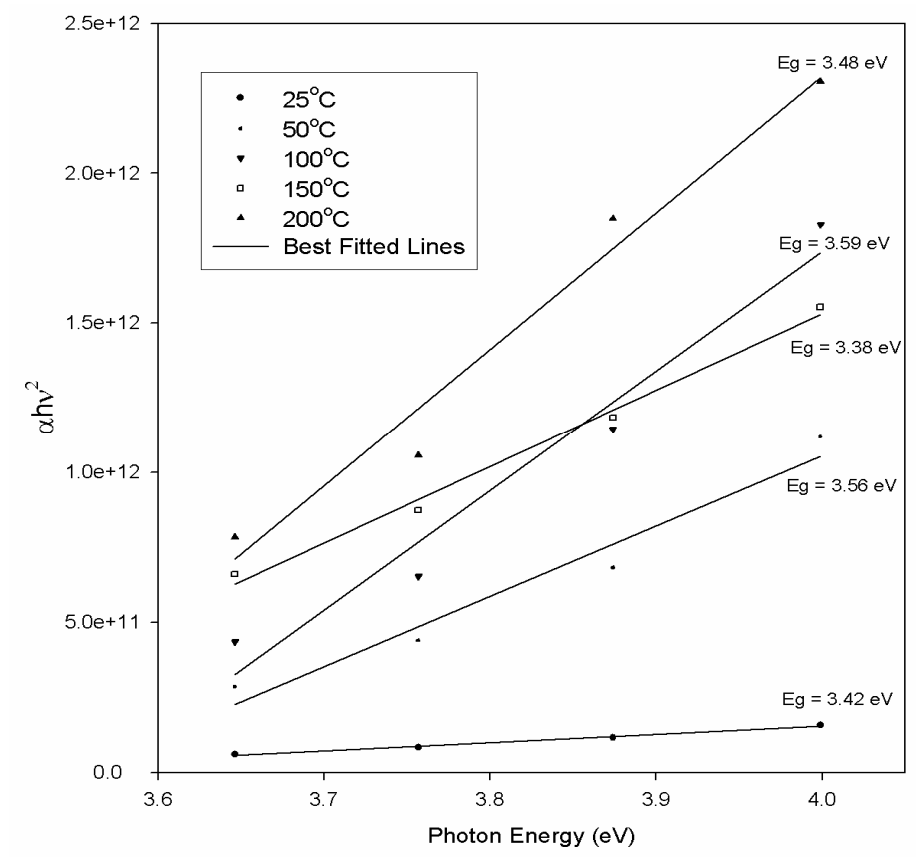

Fig. 3. Variation of $(\alpha h v)^{2}$ at various substrate temperatures with a fixed thickness of 200 nm with photon energy.

The variation of energy gap with substrate temperature is depicted in fig 4.It is observed that the band gap energy increases with substrate temperature. It is also observed that band gap energy decreases if the substrate temperature is greater than $100^{\circ} \mathrm{C}$, but it again increases when substrate temperature is greater than $150^{\circ} \mathrm{C}$. 


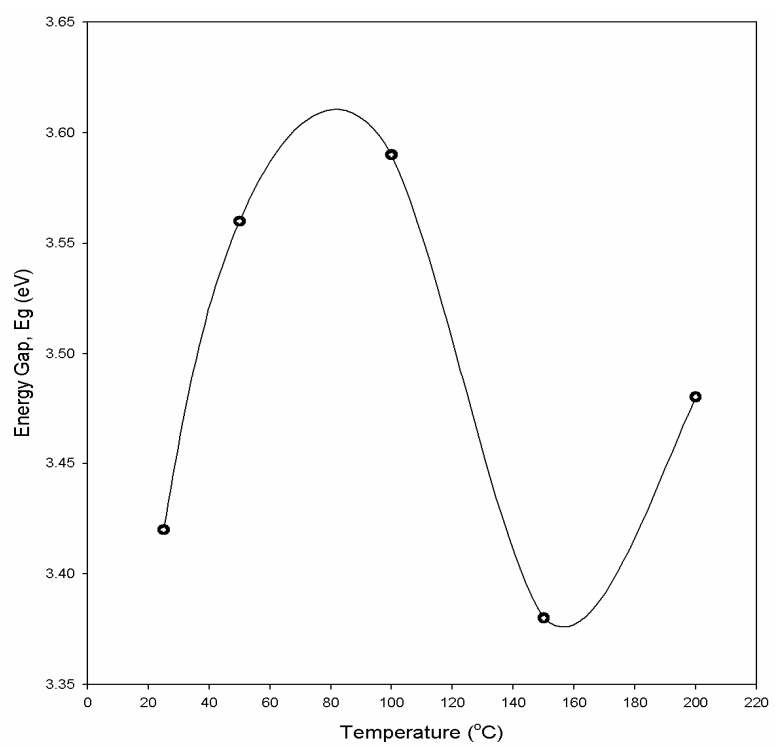

Fig. 4. Variation of energy gap $\left(\mathrm{E}_{\mathrm{g}}\right)$ of $\mathrm{SnO}_{2}$ thin films of thickness $200 \mathrm{~nm}$ with varying substrate temperature.

The results are in accordance with the findings of Shamala et al. 2004. The increment of band gap energy with substrate temperature may be attributed to the partial filling of the conduction band of tin oxide, resulting in a blocking of the lowest states. This widening of the optical band gap is termed as Burstein-Moss shift (Raghupathi et al. 2005). The shift is given by the relation.

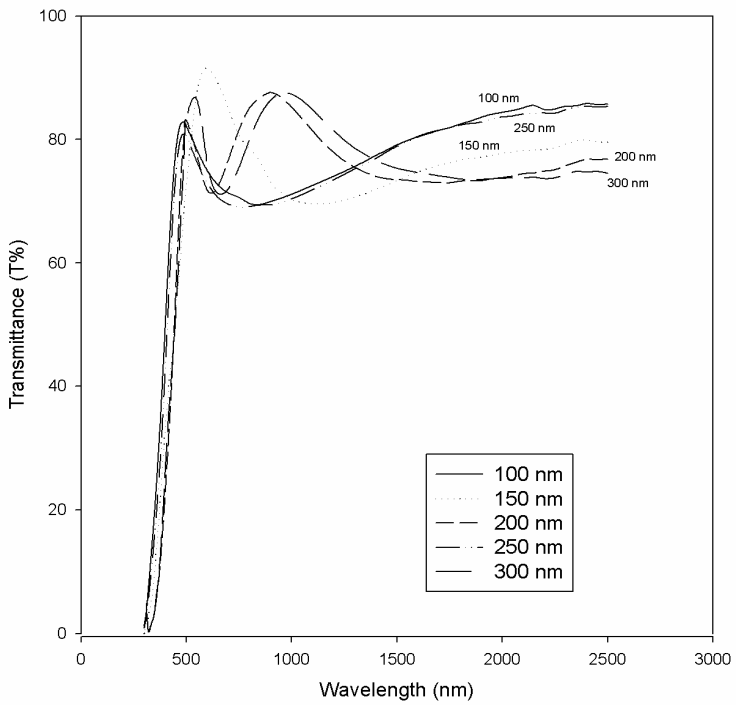

Fig. 5. Variation of optical transmittance $(\mathrm{T} \%)$ of $\mathrm{SnO}_{2}$ thin films of various thickness deposited at a substrate temperature of $100^{\circ} \mathrm{C}$ with photon wavelength. 


$$
E_{g}=E_{g o}+\Delta E_{g}^{B M}
$$

where, $\mathrm{E}_{\mathrm{go}}$ is the intrinsic band gap and $\Delta \mathrm{E}_{\mathrm{g}}{ }^{\mathrm{BM}}$ is the Burstein-Moss shift.

Fig. 5 shows the variation of transmittance with photon wavelength of tin oxide thin films of different thickness such as 100,150, 200, 250, and $300 \mathrm{~nm}$ prepared at a constant substrate temperature of $100^{\circ} \mathrm{C}$. It is observed that maximum transmittance at visible range is obtained for the thickness $100 \mathrm{~nm}(92 \%)$. But the film of thickness 200nm shows good interference pattern which indicates better homogeneity and good quality. The maximum T\% in case of the film having a thickness of $200 \mathrm{~nm}$ is slightly less than the film with thickness $100 \mathrm{~nm}$. But considering the homogeneity of the film, the film prepared at $\mathrm{T}_{\mathrm{s}}=200^{\circ} \mathrm{C}$ is considered to be better.

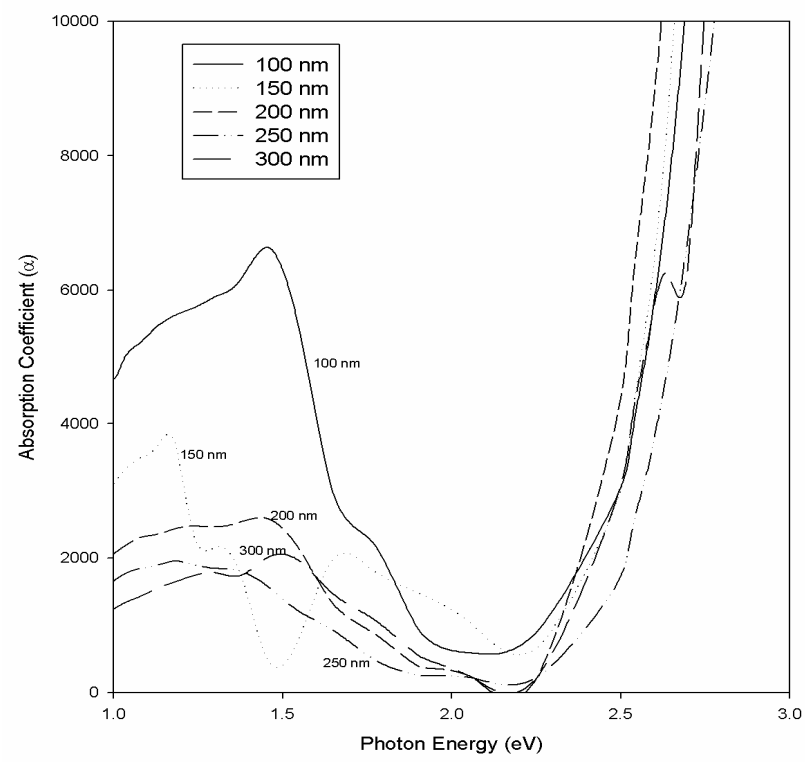

Fig. 6. Variation of absorption coefficient $(\alpha)$ of $\mathrm{SnO}_{2}$ thin films of various thickness deposited at a substrate temperature of $100^{\circ} \mathrm{C}$ with photon energy.

Fig. 6 shows the variation of absorption co-efficient with photon energy of $\mathrm{SnO}_{2}$ thin films of different thickness such as 100, 150, 200, 250, $300 \mathrm{~nm}$ prepared at constant substrate temperature $100^{\circ} \mathrm{C}$. It is observed that absorption coefficient variation is the steepest in case of thickness $200 \mathrm{~nm}$. SBG absorption is also a minimum for thickness of $200 \mathrm{~nm}$. Therefore, from these results the film of thickness $200 \mathrm{~nm}$ is considered to be better.

In Fig. 7, $(\alpha h v)^{2}$ is plotted against photon energy (hv) to find the value of band gap energy of the thin films of different thickness such as 100,150, 200, 250, $300 \mathrm{~nm}$ at constant substrate temperature $100^{\circ} \mathrm{C}$. The band gap energies of the samples of different thickness 100, 150, 200, 250 and $300 \mathrm{~nm}$ are 3.5, 3.54, 3.58, 3.6 and $3.6 \mathrm{eV}$, respectively. 


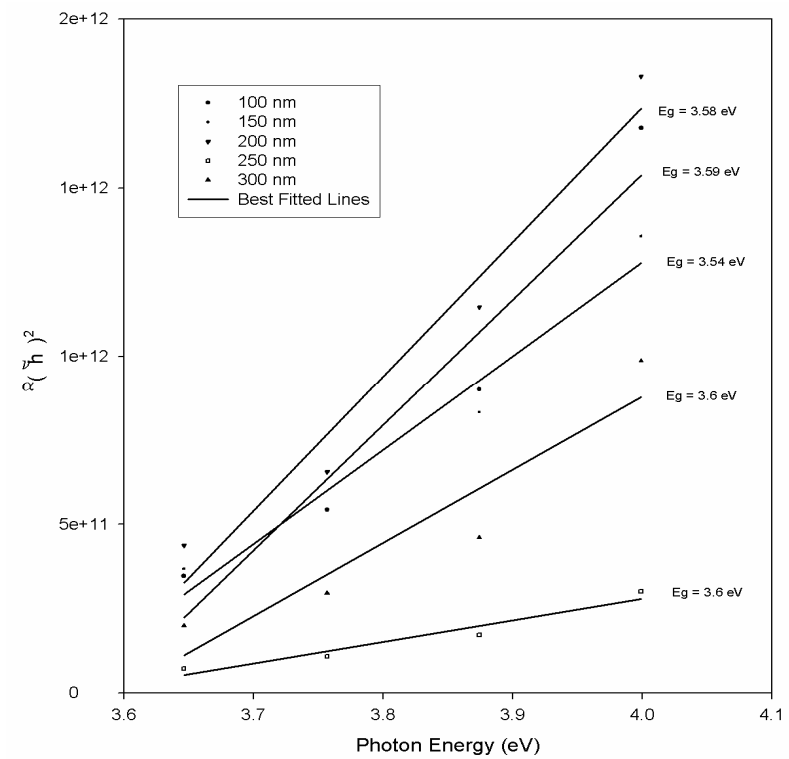

Fig. 7. Variation of $(\alpha h v)^{2}$ at various thicknesses for a fixed substrate temperature of $100^{\circ} \mathrm{C}$ with photon energy.

In Fig. 8 the energy gap variations are shown with different thickness of thin films of $\mathrm{SnO}_{2}$. It is observed that from thickness 100 to $150 \mathrm{~nm}$ the band gap energy decreases when the film thickness is increasing.

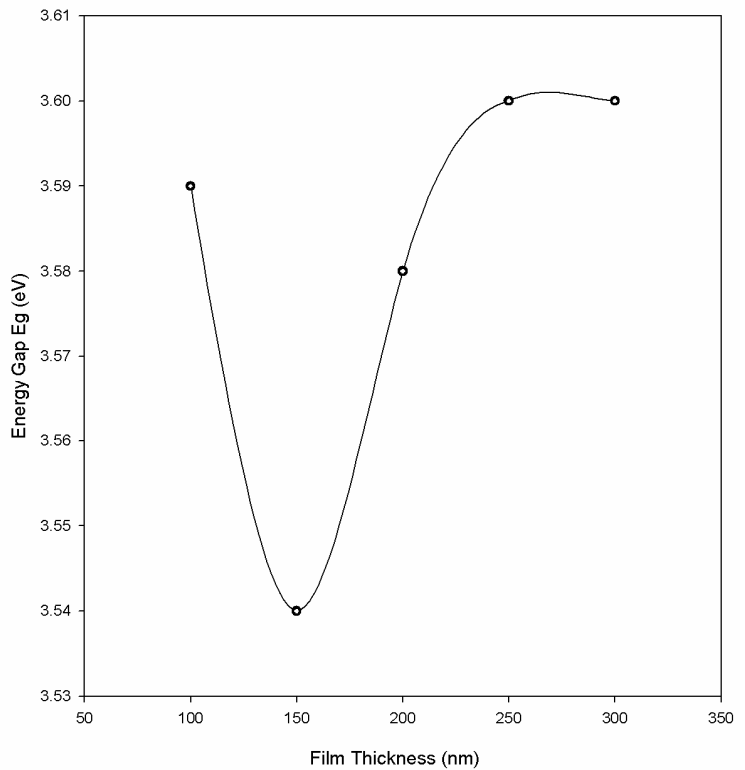

Fig. 8. Variation of energy gap $\left(\mathrm{E}_{\mathrm{g}}\right)$ of $\mathrm{SnO}_{2}$ thin films deposited at substrate temperature of $100^{\circ} \mathrm{C}$ with varying film thickness. 
But when the thickness is more than $150 \mathrm{~nm}$ the band gap energy increases with the thickness and it remains almost constant for thickness 250 and $350 \mathrm{~nm}$.

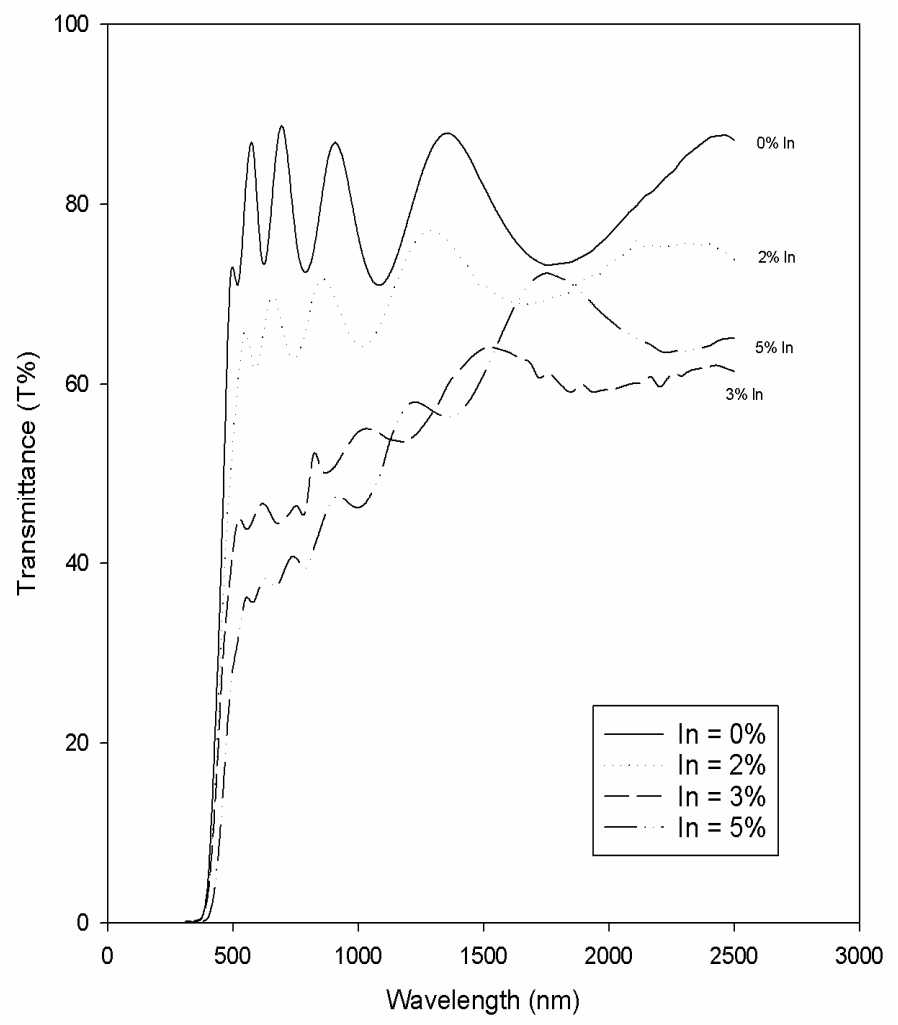

Fig. 9. Variation of optical transmittance (T\%) of indium doped $\mathrm{SnO}_{2}$ thin films at varying wt $\%$ of indium with photon wavelength.

Fig. 9 shows the variance of transmittance with photon wavelength of $\mathrm{In}$ doped $\mathrm{SnO}_{2}$ thin films where the percentage (wt\%) of In are 0,2 and $3 \%$, and thickness is constant $(710 \mathrm{~nm})$. The above deposited films were annealed at $200^{\circ} \mathrm{C}$ for 10 minutes. It is observed that the transmittance of the undoped film is highest ( $88 \%$ in the visible region). Up to $2 \%$ doping, it is good (about $72 \%$ in the visible region). But when it is more than $2 \%$ the transmittance in the visible region decreases to $40 \%$ to $50 \%$. The decrease of transmittance at higher doping concentrations may be due to the increased scattering of photons by crystal defects created by doping, which is in accordance with the findings of other workers (Manoj et al. 2007). 


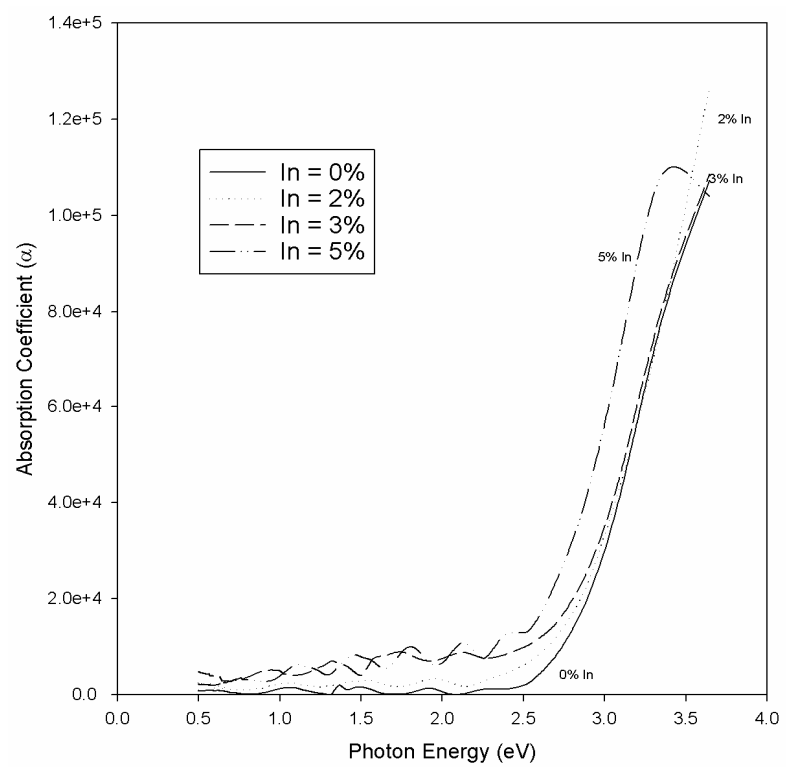

Fig. 10. Variation of absorption coefficient $(\alpha)$ of indium doped $\mathrm{SnO}_{2}$ thin films at varying wt $\%$ of indium with photon energy.

Fig. 10 shows the variation of absorption coefficient with photon energy of In doped $\mathrm{SnO}_{2}$ thin films (percentage of $\operatorname{In} 0,2,3$ and 5\%, respectively). Their thickness was kept constant $(710 \mathrm{~nm})$.

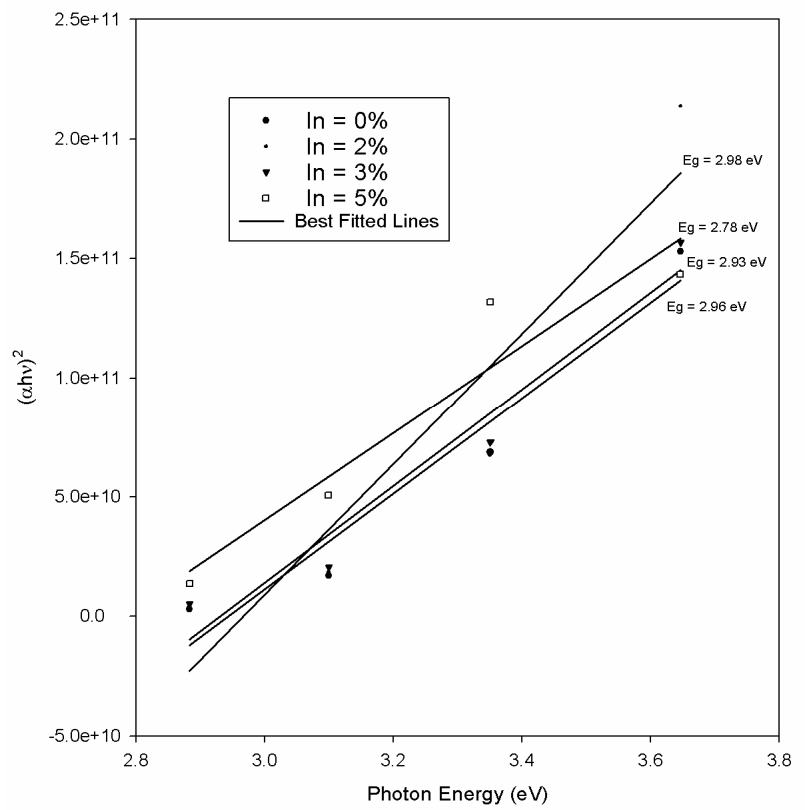

Fig. 11. Variation of $(\alpha \mathrm{hv})^{2}$ of indium doped $\mathrm{SnO}_{2}$ thin films at varying wt $\%$ of indium with photon energy. 
The above deposited films were annealed at $200^{\circ} \mathrm{C}$ for 10 minutes. The rise of absorption co-efficient with photon energy at the fundamental absorption region is the steepest in case of $2 \%$ In but SBG absorption is minimum for $0 \%$ In.

Fig. 11 shows the plot of $(\alpha h v)^{2}$ versus photon energy(hv) to find the band gap energy of the In doped $\mathrm{SnO}_{2}$ thin films. The band gap energy for different percentage of In such as $0,2,3$ and 5\% are 2.96, 2.98, 2.93 and $2.77 \mathrm{eV}$, respectively.

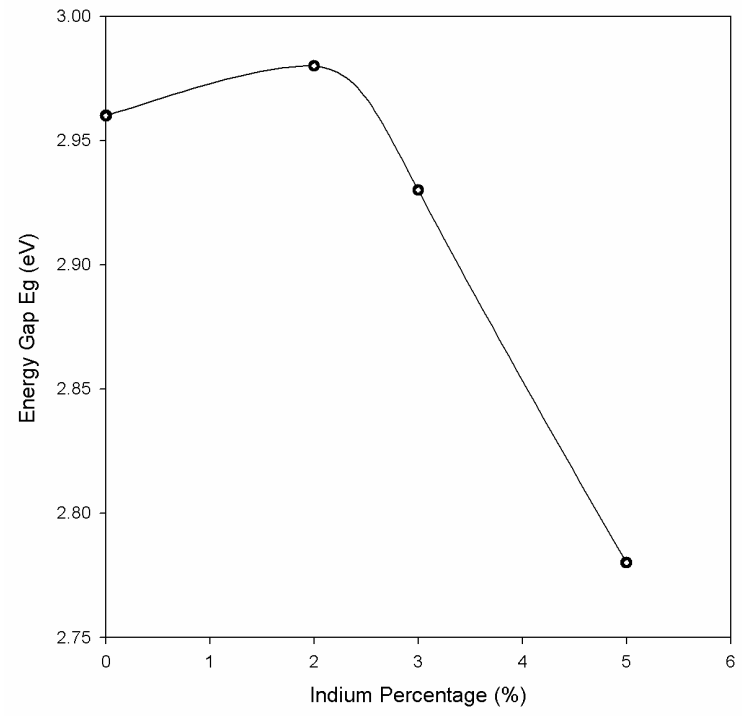

Fig. 12. Variation of energy gap $\left(\mathrm{E}_{\mathrm{g}}\right)$ of $I n$ doped $\mathrm{SnO}_{2}$ thin films with varying wt $\%$ of $I n$.

Fig. 12 shows the band gap energy of the In doped $\mathrm{SnO}_{2}$ thin films with different percentage of In. It is observed that the band gap energy increases with In percentage up to $2 \%$ then it decreases when In percentage is more than $2 \%$ which is in accordance with the findings of previous workers (Matthews, 1965).

\section{CONCLUSIONS}

Pure $\mathrm{SnO}_{2}$ thin films deposited by thermal evaporation technique exhibit an average $85 \%$ transparency in the visible region. Optical study of the films deposited at different substrate temperatures $\left(25,50,100,150,200^{\circ} \mathrm{C}\right)$ with a constant thickness of $200 \mathrm{~nm}$ shows that the film which is deposited at $100^{\circ} \mathrm{C}$ is superior in quality than the others.

It is found that the film of $200 \mathrm{~nm}$ deposit at $200^{\circ} \mathrm{C}$ gives minimum SBG absorption and good interference pattern.

The optical measurement of In doped $\mathrm{SnO}_{2}$ thin films where the wt $\%$ of In are 0,2 , 3 and 5\% show that transmittance decreases with increasing In content. The band gap energy increases up to $2 \mathrm{wt} \%$ of $I n$ but decreases for the wt $\%$ of In more than 2. 
From the above investigations, it may be concluded that undoped film having thickness of $200 \mathrm{~nm}$ prepared at substrate temperature $100^{\circ} \mathrm{C}$ yield essential acceptable properties for photovoltaic application.

\section{ACKNOWLEDGEMENT}

The authors thank Experimental Physics Division of Atomic Energy Centre, Dhaka for carrying out this research work.

\section{REFERENCES}

Afify, H.H., F. S. Terra and R. S. Momtaz. 1996. Substrate temperature effects on the tin oxide films prepared by spray pyrolysis. Journal of Materials Science: Materials in Electronics 7(2): 149.

Alam, M. J. and D.C. Cameroon. 2000. Optical and electrical properties of transparent conductive ITO thin films deposited by sol-gel process. Thin Solid Films 377-378: 455-459.

Debajyoti, Das and R. Banerjee. 1987. Properties of Electron Beam Evaporated Tin oxide Films. Thin Solid Films. 147: 321.

Elangovan, E. and K. Ramamurthi. 2003. Optoelectronic properties of spray deposited SnO 2: F thin films for window materials in solar cells. J. Optoelectronics and Advanced Materials 5(1): 45-54.

Heavens, O. S. 1959. Evaporation of metals by electron bombardment. J. Sci. Instr. 36(2): 95.

Jeong-Woon Bae, Sang Duk Park, Nam Gil Cho, Do Haing Lee and Geun Young Yeom. 2002. Effects of Tin Concentration on the Electrical Properties of Room-Temperature Ion-BeamAssisted-Evaporation-Deposited Indium Oxide Thin Films. Jpn. J. Appl. Phys. 41, L999L1001.

Lee, W. J., Y.K Fang, J.J. Ho, C.Y. Chen, S.F. Chen, R.Y. Tsai, D. Huang and F. C. Ho. Optimizing indium tin oxide thin films with bipolar d.c.-pulsed magnetron sputtering for electrochromic device applications. J. Material Sciences: Materials in Electronics 13(12): 751.

Legnani, C., S.A.M. Lima, H.H.S. Oliveira, W.G. Quirino, R. Machado, R.M.B. Santos, M.R. Davolos, C.A. Achete, and M. Cremona. 2007. Indium tin oxide films prepared via wet chemical route. Thin Solid Films 516(2-4): 193-197.

Manoj, P.K., Benny Joseph, V.K. Vaidyan and D. Sumangala Devi Amma. 2007. Preparation and characterization of indium-doped tin oxide thin films. Ceramics International. 33(2), 273.

Mika Yamaguchi, A. Ide-Ektessabi, H.Nomura and N. Yasui. 2004. Characteristics of indium tin oxide thin films prepared using electron beam evaporation. Thin solid films 447-448: 115.

Nunes P. 2001. Properties Presented by Tin Oxide Thin Films Deposited by Spray Pyrolysis. Solid State Phenomena 80: 139.

Raghupathi, P. S., Joseph George and C.S. Menon. 2005. Effect of substrate temperature on the optical and electrical properties of reactively evaporated tin oxide films. Indian Journal of Pure and Appl. Phys. 43: 620.

Shamala, K. S., L.C.S. Murthy and K. Narashimha Rao. 2004. Studies on tin oxide films prepared by electron beam evaporation and spray pyrolysis methods. Bull. Mater. Sci. 27(3): 295-301.

Tomlin, S.G., 1972. Determination of the optical constants of thin absorbing films. Thin Solid Films 13(2): 265-268.

(Received revised manuscript on 28 April, 2011) 